\title{
IMPROVED WEAR PERFORMANCE OF ULTRA HIGH MOLECULAR WEIGHT POLYETHYLENE COATED WITH HYDROGENATED DIAMOND LIKE CARBON
}

\author{
1,2* Puértolas J A; ${ }^{1}$ Martínez V; ${ }^{1}$ Martínez M J; ${ }^{1}$ Mariscal, M D; \\ ${ }^{2}$ Medel, F J, ${ }^{3}$ López, C; ${ }^{3}$ Yubero, F
}

${ }^{1}$ Department of Materials Science and Technology, Instituto de Investigaciones en Ingeniería de Aragón, I3A, Universidad de Zaragoza, E-50018 Zaragoza, Spain.
${ }^{2}$ Department of Materials Science and Technology, Instituto de Ciencia de Materiales de Aragón, ICMA, Universidad de Zaragoza-CSIC, E-50012 Zaragoza, Spain.
${ }^{3}$ Instituto de Ciencia de Materiales de Sevilla (CSIC- U. Sevilla). C/Américo Vespucio 49, E- 41092 Sevilla, Spain.

*Correspondence to J.A. Puértolas, Full Professor

Tel. : 34976 762521; Fax. : 34976 761957;

e-mail: japr@unizar.es 


\begin{abstract}
Hydrogenated diamond like carbon (DLCH) thin films were deposited on medical grade ultra high molecular weight polyethylene (UHMWPE) by radio frequency plasma enhanced chemical vapour deposition. The DLCH-coating thicknesses ranged from 250 to $700 \mathrm{~nm}$. The substrates were discs made of UHMWPEs typically used for soft components in artificial joints, namely virgin GUR 1050 and highly crosslinked (gamma irradiated in air to $100 \mathrm{kGy}$ ) UHMWPEs. Mechanical and tribological properties under bovine serum lubrication at body temperature were assessed on coated and uncoated polyethylenes by means of nanohardness and ball-on-disk tests, respectively. Morphological features of the worn surfaces were obtained by confocal microscopy and scanning electron microscopy. This study confirm an increase in surface hardness and good wear resistance for coated materials after 24 hours of sliding test compared to uncoated polyethylene. These results point out that to coat UHMWPE with DLCH films could be a potential method to reduce backside wear in total hip and knee arthroplasties.
\end{abstract}




\section{INTRODUCTION}

Ultra high molecular weight polyethylene (UHMWPE) is the most relevant bearing material used in total hip and knee replacements due to its physical, chemical, and mechanical properties, as well as biocompatibility [1-2]. However, UHMWPE has been the weak material of total joint replacements throughout the years, because of wear-related problems [3] and mechanical degradation after long-term post-irradiation oxidation [4]. The former problem stems from the inevitable generation of polyethylene debris particles, which worn off the soft component after repeated cyclic bearing. These particles trigger a cascade of adverse biological reactions in the human body, which may cause the eventual loosening of the component, and therefore, revision of the prosthesis $[3,5]$.

Wear of articular surfaces has been recognized as the main responsible for the production of polyethylene particles. Particle production from other non-articular surfaces in modular implants has also been observed [6]. This secondary wear source relates to micromobility in modular junctions due to insufficiency of locking mechanisms during service [7]. Although first detected in hip replacements, this problem increasingly affects the knee, with polyethylene particle production estimations for non-articular surfaces being 2 to 100 times the femorotibial wear [8]. Moreover, retrieved knee implants showed non-articular wear 2 to 4 times higher than that of hip implants [9]. Changes in locking mechanisms to limit microdisplacements (from 5 to 311 microns for hip prostheses) and subsequent wear [10] are more difficult at the knee. Other options such as polishing the tibial tray may only be feasible in flat surfaces, but not in metal irregularities [11]. A potential solution for this problem might be to coat non-articular surfaces of polyethylene implants with low friction and wear resistant films.

Highly crosslinked polyethylene (HXLPE) exhibits improved wear resistance due to an elevated crosslink density achieved by gamma or electron beam irradiation to doses ranging 50$100 \mathrm{kGy}$ [12]. However, the irradiation process also originates free radicals [13], whose thermal stabilization produces a negative effect on the fatigue and toughness properties of UHMWPE [14-15]. On the other hand, although HXLPE has shown greatly reduced wear volumes, 
paradoxically it also exhibits decreased wear debris size, which may have the potential to increase biological activity and, then, to aggravate osteolytic reactions [16-17].

Hydrogenated diamond like carbon (DLCH) coatings have shown good performance regarding hardness, wear resistance, friction, chemical inertness and good biocompatibility, which make them a good option for implants in biomedical applications [18-19]. DLCH consists of amorphous carbon with a significant fraction of $\mathrm{C}-\mathrm{C} \mathrm{sp}{ }^{3}$ bonds and $\mathrm{H}$ content in the 20-40 at. $\%$ [20]. In this field, DLCH coatings on metallic materials, which typically form a bearing couple with UHMWPE, have been developed to reduce the wear rate and corrosion of metallic components in prosthetic applications. However, while the second goal is achieved by DLCH coatings, the first one presents a strong controversy taken into account the results obtained in the laboratory and even in clinical trials. Both positive and negative wear behaviors have been reported in the last decade [18] from pin/ball-on-disks, simulator and "in vivo“ studies for 316L, CoCrMo and Ti6Al4V materials as the metallic counterpart of UHMWPE in articulating components. Although some of the discrepancies are attributed to the use of different lubricants as well as the DLCH composition, structure and other experimental conditions, the fact is that some modern knee replacements have been recalled after clinical reports documenting DLCH coating failures. In consequence, new alternatives based on DLCH coated UHMWPE for nonarticulating surfaces must be promoted, maintaining the good performance of UHMWPE in total hip and knee replacements.

DLCH coatings on UHMWPE have been prepared by pulsed arc plasma physical vapor deposition (PVD) [21], plasma source ion implantation [22] and plasma enhanced chemical vapor deposition (PECVD) [23-24]. In the latter case, good adhesion and high mechanical performances has been reported. The hypothesis of this work focuses on the use of DLCH coated UHMWPE to decrease the risk of osteolysis in modular implants, reducing the particle formation from non-articular surfaces. To accomplish these goals, pristine and highly cross linked UHMWPE were coated with DLCH layers with different thicknesses and their surface nanohardness and tribological behaviors were analyzed. 


\section{MATERIALS AND METHODS}

Raw and irradiated UHMWPE sample preparation

The raw material used in this study was a compression-molded sheet of GUR 1050 UHMWPE (Perplas Medical Ltd., Lancashire UK). Discs $3 \mathrm{~mm}$ thick and $20 \mathrm{~mm}$ in diameter were machined from the compression-molded sheet. Before irradiation, all discs were ground and polished using $\mathrm{SiC}$ papers up to a surface roughness equal to $0.15 \pm 0.05$ microns. Afterwards, they were gamma irradiated in air (I) to a final dose of $100 \mathrm{kGy}$ (Aragogamma, Barcelona, Spain).

\section{DLCH coatings}

DLCH thin films were deposited on pristine and gamma irradiated UHMWPE by PECVD in a RF capacitive coupled reactor with plate parallel electrodes. DLCH layers of 250 and $700 \mathrm{~nm}$ were deposited on pristine (V) and irradiated (I) substrates using acetylene, Ar, and $\mathrm{H}_{2}$ gas mixture and $200 \mathrm{~V}$ bias voltage. Thus, the different material groups included in this study were referred to as V, V250, V700, I, I250 and I700,

To achieve good adhesion between DLCH coatings and polyethylene substrates, an Ar plasma was applied to the UHMWPE samples to activate their surface, and a very thin (less than $20 \mathrm{~nm}$ ) $\mathrm{H}$ rich DLCH accommodation layer was deposited using the same gas mixture and an increasing bias voltage between $100 \mathrm{~V}$ and $200 \mathrm{~V}$, prior to the DLCH deposition process.

Several techniques were used to characterize the DLCH coatings. Their H content (about 20 at. $\%$ ) and density (about $1.8 \mathrm{gr} / \mathrm{cm}^{3}$ ) was evaluated using a combined analysis of X-ray photoelectron and reflection electron energy loss spectroscopies [25]. Other bonding characteristics of the final DLCH layers were evaluated using visible (514 nm) Raman spectroscopy. 
Nano-hardness profiles.

In-depth hardness profiles of uncoated and DLCH coated UHMWPE samples were obtained using a nanoindenter XP MTS system. The maximum loads used in the tests were 0.5 and $2.0 \mathrm{mN}$, depending on the samples. The depth rate was $5 \mathrm{~nm} / \mathrm{s}$.

\section{Wear experiments}

A commercial pin-on-disc tribometer (CSM instruments; Peseux, Switzerland) allowed assessing wear resistance and constantly monitoring the coefficient of friction for all materials. Wear tests were performed in at least three samples per material group working with a rotating vessel, which contained UHMWPE discs immersed in bovine serum (B-9433, Sigma Aldrich). The counterpart was a stationary ball, $6 \mathrm{~mm}$ in diameter, made of alumina with a roughness, Ra, of $0.05 \pm 0.002 \mu \mathrm{m}$, whereas the load applied to the ball was $5.23 \mathrm{~N}$. The radius of the circular track was $4 \mathrm{~mm}$ and the sliding speed was $0.05 \mathrm{~m} / \mathrm{s}$. The environment temperature was set to 37 ${ }^{\circ} \mathrm{C}$, the body temperature. Assuming hertzian contact, the previous loading conditions gave an approximate contact pressure of $37 \mathrm{MPa}$, which is in the range of peak contact stresses ( $\geq 30$ MPa) found for some contemporary polyethylene tibial inserts [26-27]. Nevertheless, the current experimental conditions did not represent an excessively severe tribological testing, as the global severity parameter proposed by da Silva and Sinatora lain out of the thermal failure regime for our test conditions [28]. Wear rates were measured after 12, 68 and $4400 \mathrm{~m}$ sliding distances. After each wear test, disks were removed from the tribometer and underwent a cleaning protocol following guidelines included in ASTM F2025.

Confocal microscopy was performed using a SENSOFAR PLU 2300 optical imaging profiler and served to evaluate worn disc surfaces. Four line measurements diametrically opposed were carried out on the wear tracks of each sample. The average of the registered worn areas was used to calculate wear factors, $k$, according to the following equation:

$$
\left.k=\frac{2 \pi r A_{m}}{L s} \text { (eq. } 1\right)
$$

where $r$ is the wear track radius, $A_{m}$ is the average worn area, $L$ is the applied load, and $s$ is the sliding distance. 
The volume loss corresponding to the track profile was evaluated taking into account the plastic deformation suffered by the polyethylene discs under applied loads during wear tests. By virtue of the shape memory effect, UHMWPE and HXLPE heated to high enough temperature recover the original shape that has been previously lost due to mechanical deformation [29]. The recovery of plastic deformation after wear testing was achieved by heating samples at $120{ }^{\circ} \mathrm{C}$ for 36 hours. Preliminary tests confirmed that some DLCH coated samples demonstrated no removal of the DLCH layer after tribological testing, but they exhibited wear tracks exclusively due to permanent plastic deformation. This permanent plastic deformation was not completely recovered after the thermal treatment. Thus, the area $A_{m}$ introduced in equation (1) was the average worn area after the heating process and then corrected taking into account the nonrecoverable plastic deformation.

Student's t tests (or Wilcoxon tests when appropriate) served to detect significant differences between the friction coefficient and wear factor results of both uncoated and DLCH coated UHMWPE samples. P values less than 0.05 were considered indicative of significance.

\section{Microscopy observation}

Environmental scanning electron microscopy (SEM) equipment (HITACHI S-3400 N) was used to observe the morphology of the wear tracks in all the samples.

\section{RESULTS AND DISCUSSION}

\section{Characteristics of the DLCH coatings}

Figure 1 shows the typical Raman spectrum registered for DLCH coatings. It showed the

characteristic $G$ peak at $\sim 1530 \mathrm{~cm}^{-1}$ and a $D$ peak at $\sim 1328 \mathrm{~cm}^{-1}$, with a $A(D) / A(G)$ intensity ratio of 0.63 . This result is consistent with a $\mathrm{DLCH}$ with $30-40 \%$ of $\mathrm{C}-\mathrm{C} \mathrm{sp}{ }^{3}$ bonds, and $\mathrm{H}$ content of about 20 at. $\%$ and density of about $1.8 \mathrm{gr} / \mathrm{cm}^{3}$ [20].

\section{Nano-hardness}

Figure 2 shows the nano-hardness profiles obtained for uncoated and DLCH coated UHMWPE samples. Qualitatively, a similar behavior was observed regardless of the substrate 
materials, i.e. virgin or irradiated polyethylene, although nano-hardness in the latter was slightly higher than that of specimens corresponding to virgin substrates. Nano-hardness tests of uncoated samples showed a start-up value of $\sim 1 \mathrm{GPa}$, which rapidly decreased until a constant value was reached. In virgin samples this value was $0.01 \mathrm{GPa}$ and was reached at a depth of 60 $\mathrm{nm}$, whereas in crosslinked polyethylene the value was $0.04 \mathrm{GPa}$ and reached at $150 \mathrm{~nm}$. These small hardness values are consistent with those obtained for UHMWPE commonly utilized for acetabular liners.

Other general property deduced from nanoindentation profiles was that the overall hardness significantly rose with the thickness of the coatings. The V250 and I250 samples presented similar nano-hardness profiles with an initial decrease that finished in a well, which was, in turn, followed by a wide shoulder. In both coated materials the initial hardness was close to $2 \mathrm{GPa}$, the minimum appeared at $15 \mathrm{~nm}$ and the shoulder around $40 \mathrm{~nm}$, although the well was more pronounced in V250 samples than in the I250 ones. From $300 \mathrm{~nm}$ in depth, hardness reached a steady value of $0.1 \mathrm{GPa}$, which was higher than the one displayed by uncoated samples. In samples with the thickest DLCH coatings, V700 and I700, the well disappeared, and after an initial and strong fall, the hardness followed a smooth decrease up to a value of $\sim 0.3$ $\mathrm{GPa}$ at $400 \mathrm{~nm}$ in depth.

The present findings confirmed the strong influence of the substrate material, particularly when the coating and substrate stiffnesses are very different, as happens between DLCH and polyethylene. On the other hand, it is usual that the influence of the substrate becomes relevant at indentation depths higher than $15 \%$ of the coating thickness, which coincides with the depth where the V250 and I250 samples underwent the shoulder. The other part of the profile where there was a significant improvement in hardness was the uppermost surface. However, this observed hardening was lower than the one obtained by Poliakov and colleagues for DLCH films with $250 \mathrm{~nm}$ thickness deposited on UHMWPE [21], although its shape profiles were closer to the ones depicted in our V700 and I700 samples. Probably, the reason for the relative softening is the lower sp3 content of the DLCH grown with PECVD compared with that obtained by pulse arc plasma PVD. 


\section{$\underline{\text { Friction }}$}

The dependence of the friction coefficient $f$ versus sliding time obtained during ball-ondisk testing is plotted in Figures $3 \mathrm{a}$ and $3 \mathrm{~b}$ for the six materials. Uncoated virgin (V) and crosslinked (I) polyethylene samples exhibited the lowest friction coefficients at the beginning of the test, 0.10 and 0.12 , respectively (Wilcoxon test; $p \leq 0.03$ with respect to DLCH coated materials). Later on, the friction behavior remained practically constant for uncoated specimens during all the sliding distance. DLCH coated materials with a $700 \mathrm{~nm}$ layer displayed the highest friction coefficients (close to 0.20 ), which remained practically constant throughout the whole sliding distance. This friction coefficient was higher than those reported previously for DLCH coatings on steel substrates sliding against alumina counterpart in normal atmosphere, which ranged between 0.06 and 0.15 depending on the applied load and sliding velocity conditions [30-31]. The dynamic friction coefficient spectra of $250 \mathrm{~nm}$ coated materials revealed a different tribological behavior. Specimens with the thinnest DLCH layers started with a friction coefficient $(\sim 0.20)$ similar to that of $700 \mathrm{~nm}$ DLCH coated materials (Wilcoxon test; $\mathrm{p} \geq 0.4$ ). Then, the initial friction coefficient of $250 \mathrm{~nm}$ DLCH coated materials progressively reduced down to about 0.11 (the steady friction coefficient of uncoated materials), especially in the case of irradiated substrates $(\mathrm{p}=0.24$; I250 compared with I materials at the end of wear testing). These findings point out that the DLCH layer became unstable during sliding in a process that finished when the ball reached the substrate, and therefore the friction coefficient reflected that of the polyethylene/alumina bearing couple. Previous long-term tribological tests have also shown sudden jumps in the friction coefficient [30], although the comparison with the

present study is not fully appropriate since the initial surface roughness of our polyethylene specimens was higher than that of the metallic substrates used in previous studies for DLCH coating. Other variables like liquid lubrication, temperature and DLCH composition could also affect the wear life of the coating.

$\underline{\text { Wear }}$

Confocal microscopy images of the wear tracks were obtained for the six materials after $4400 \mathrm{~m}$ of sliding distance (Figure 4a-f). Uncoated virgin and crosslinked UHMWPE samples exhibited wear tracks with grooves parallel to the sliding direction, which are typical of an 
abrasive wear process (Figures $4 \mathrm{a}$ and $4 \mathrm{~b}$, respectively). Figures $4 \mathrm{e}$ and $4 \mathrm{f}$ illustrate that wear traces of coated V700 and I700 samples were less visible than those produced in uncoated samples, although they kept a similar morphology. Finally, the confocal micrographs corresponding to wear tracks of coated I250 (Figure $4 \mathrm{~d}$ ) materials show that the DLCH layer was fully removed, whereas the coating of V250 samples (Figure 4c) was only partially removed. In all the cases, the ball surface exhibited no polymeric transfer layer. This observation agrees with the absence of strong fluctuations in the friction coefficient during the running-in period. On the other hand, the proteins of bovine serum lubrication could inhibit the built-up of a transfer layer, as it happens in polyethylene-metallic bearing couples. In these cases, the friction coefficient keeps its initial value during the whole wear experiment [32]. On the contrary, Gispert and coworkers have recently reported a polymeric transfer layer and changes in the friction coefficient in a wear experiment using a solution of bovine serum albumin as lubricant [33].

Planar view SEM images were also taken for the surface of uncoated and DLCH coated samples before tribological characterization to compare them with images corresponding to the wear track. In Figures 5 a-c we only show micrographs corresponding to V, V250 and V700 specimens, respectively, since no significant differences were observed for highly crosslinked samples before testing. Uncoated samples presented a homogeneous morphology (Figure 5a), whereas the surface of the DLCH coatings showed a faceted structure of about 2-5 microns size (Figure $5 \mathrm{~b}-\mathrm{c})$, which was similar to that reported for very thin DLCH films $(\sim 50 \mathrm{~nm})$ deposited on high density polyethylene [34]. After wear testing, the morphology of uncoated samples featured regions of plastic deformation as well as the presence of cracks and flakes, which were more pronounced in irradiated samples (Figures 6a-b). A mix of two phases appeared into the tracks of V250 samples (Figures 6c-d), in agreement with the partial removal of the DLCH layer, although the dark part of this image did not depicted the structure of the DLCH coating exhibited in Figures 4b, and 4c before wear testing. SEM observations of the bottom of the wear tracks for $700 \mathrm{~nm}$ thick DLCH coated polyethylene pointed out the presence of the same initial structure although grooved by long channels a few microns wide (Figures 6 e-f). These channels were more pronounced in non-irradiated substrates (Figure 6e). The comparison between the morphologies observed before and after testing confirmed that the thickest DLCH coatings 
remained onto polyethylene substrates after 24 hours of sliding. This finding could explain the fact that the friction coefficient for V700 and I700 samples corresponded to that of the DLCH/alumina bearing couple. According to this idea, the wear track observed by confocal microscopy should correspond with a volume loss of DLCH coating. However, the measured track dimensions, $500 \mu \mathrm{m} \times 5 \mu \mathrm{m}$, proved the former statement erroneous. Cryogenic fractures were carried out in a perpendicular plane to the worn surface of the disks to show cross sections of the coatings after tribological testing. Figures 7a-b show typical micrographs for V700 samples before and after wear testing, respectively. In these images, the DLCH layer can easily be distinguished from the polyethylene substrate and the resin used for sample preparation. The layer thickness (close to $700 \mathrm{~nm}$ ) was equal in both cases, out of and in the wear track. However, while the DLCH layer appeared relatively intact and continuous out of the wear track (Figure 7a), it was fractured in regions corresponding to the wear track (Figure 7b). A similar behavior occurred for V250 and I250 samples but only after $68 \mathrm{~m}$ of sliding. In all these cases, the dimensions of the remaining wear tracks after the thermal process allowed us to determine the permanent deformation, which polyethylene underwent during testing, which is, in turn, associated to its viscoelastic behavior.

The wear performance of the samples included in this work is summarized in Table 1. Wear factors were calculated taking into account the different sliding lengths and, bearing in mind the shape memory effect, i.e., the permanent deformation corrections. A conclusion that can be drawn from these data is that the wear rate, $k$, decreased with the sliding distance. This can be explained by an initial polishing of the sample and an associated increment of the contact area that results in reduced contact pressure. Another characteristic of the wear behavior is that, at sliding distances shorter than $12 \mathrm{~m}$, irradiated samples showed a lower wear factor than virgin samples. The morphologies of the wear tracks of virgin and irradiated samples as observed by SEM also confirmed that crosslinked UHMWPE showed an improved wear resistance with respect to pristine UHMWPE, and therefore it constitutes a good substrate for thin coatings. In general, gamma and electron-beam irradiation are methods that allow simultaneous sterilization and wear resistance improvement of UHWMPE. However, since wear is not an intrinsic property of the material, but a property associated to a bearing couple in specific lubrication and loading conditions, it is possible to find opposite behaviors when one of the components of the 
system is changed. In fact, Zhu and colleagues observed a better behavior for HXLPE as compared to a non-crosslinked UHMWPE when articulating against metallic and DLCH counterparts, while the behavior was the opposite against alumina [35]. Besides this former

finding, Table 1 shows also the most relevant result, that is, DLCH coatings significantly enhanced the wear resistance regardless of the substrate, virgin or irradiated polyethylene, corroborating the hypothesis of the current work. This effect was more relevant for V700 and I700 samples with the thickest DLCH coatings (Student's $t$ test; $p<0.05$ and $p<0.0004$, respectively, for comparisons with uncoated materials). These promising results guarantee further research, including additional wear tests where DLCH bears against either Ti, Ti6Al4V or $\mathrm{CoCr}$ alloys as counterpart. More suitable wear tests reproducing micromotions that take place between the polymeric component and the metallic tray in modular implants will be also considered.

\section{CONCLUSIONS}

Hydrogenated diamond like carbon coated pristine and highly crosslinked UHMWPE samples presented improved wear performances compared with uncoated materials. Tribological analyses revealed that $700 \mathrm{~nm}$ thick DLCH coatings were efficient to significantly enhance the wear resistance of UHMWPE, although the friction coefficients in this case were higher than those of uncoated samples. DLCH coatings showed good adhesion to the substrates as confirmed by nano-hardness analysis and surface morphology studies performed by SEM and confocal microscopy. Therefore, DLCH coatings appear to be potential candidates to reduce backside wear in modular implants.

\section{ACKNOWLEDGEMENTS}

We thank the Ministry of Science and Education of Spain (projects MAT2006-12603C02-01 and CONSOLIDER project CSD2008-00023 (FUNCOAT) for financial support. 


\section{REFERENCES}

1. Lewis G. Properties of crosslinked ultra-high-molecular-weight polyethylene. Biomaterials 2001;22(4):371-401.

2. Kurtz SM, Muratoglu OK, Evans M, Edidin AA. Advances in the processing, sterilization, and crosslinking of ultra-high molecular weight polyethylene for total joint arthroplasty. Biomaterials 1999;20(18):1659-1688.

3. Kilgus DJ, Moreland JR, Finerman GA, Funahashi TT, Tipton JS. Catastrophic wear of tibial polyethylene inserts. Clin Orthop Relat Res 1991(273):223-231.

4. Kurtz SM. The UHMWPE Biomaterials Handbook: Ultra-High Molecular Weight Polyethylene in Total Joint Replacement and Medical Devices (2nd Edition). Burlington, MA: Academic Press, 2009.

5. Sochart DH. Relationship of acetabular wear to osteolysis and loosening in total hip arthroplasty. Clin Orthop Relat Res 1999(363):135-150.

6. Huk OL, Bansal M, Betts F, Rimnac CM, Lieberman JR, Huo MH, et al. Polyethylene and metal debris generated by non-articulating surfaces of modular acetabular components. $\mathrm{J}$ Bone Joint Surg Br 1994;76(4):568-574.

7. Engh GA, Lounici S, Rao AR, Collier MB. In vivo deterioration of tibial baseplate locking mechanisms in contemporary modular total knee components. J Bone Joint Surg Am 2001;83-A(11):1660-1665.

8. Rao AR, Engh GA, Collier MB, Lounici S. Tibial interface wear in retrieved total knee components and correlations with modular insert motion. J Bone Joint Surg Am 2002;84A(10):1849-1855.

9. Li S, Scuderi G, Furman BD, Bhattacharyya S, Schmieg JJ, Insall JN. Assessment of backside wear from the analysis of 55 retrieved tibial inserts. Clin Orthop Relat Res 2002(404):75-82.

10. Fehring TK, Smith SE, Braun ER, Mobley C, Wang PL, Griffin WL. Motion at the modular acetabular shell and liner interface. A comparative study. Clin Orthop Relat Res 1999(367):306-314.

11. Conditt MA, Stein JA, Noble PC. Factors affecting the severity of backside wear of modular tibial inserts. J Bone Joint Surg Am 2004;86-A(2):305-311.

12. McKellop H, Shen FW, Lu B, Campbell P, Salovey R. Development of an extremely wear-resistant ultra high molecular weight polyethylene for total hip replacements. J Orthop Res 1999;17(2):157-167.

13. Premnath V, Harris WH, Jasty M, Merrill EW. Gamma sterilization of UHMWPE articular implants: an analysis of the oxidation problem. Ultra High Molecular Weight Poly Ethylene. Biomaterials 1996;17(18):1741-1753.

14. Ries MD, Pruitt L. Effect of cross-linking on the microstructure and mechanical properties of ultra-high molecular weight polyethylene. Clin Orthop Relat Res 2005;440:149156.

15. Medel FJ, Pena P, Cegonino J, Gomez-Barrena E, Puertolas JA. Comparative fatigue behavior and toughness of remelted and annealed highly crosslinked polyethylenes. J Biomed Mater Res B Appl Biomater 2007;83(2):380-390.

16. Ries MD. Highly cross-linked polyethylene: the debate is over--in opposition. J Arthroplasty 2005;20(4 Suppl 2):59-62. 
17. Jasty M, Rubash HE, Muratoglu O. Highly cross-linked polyethylene: the debate is over-in the affirmative. J Arthroplasty 2005;20(4 Suppl 2):55-58.

18. Roy RK, Lee KR. Biomedical applications of diamond-like carbon coatings: a review. J Biomed Mater Res B Appl Biomater 2007;83(1):72-84.

19. Hauert R. An overview on the tribological behavior of diamond-like carbon in technical and medical applications. Tribology International 2004;37(11-12):991-1003.

20. Casiraghi C, Ferrari AC, Robertson J. Raman spectroscopy of hydrogenated amorphous carbons. Physical Review B 2005;72(8).

21. Poliakov VP, de Siqueira CJ, Veiga W, Hummelgen IA, Lepienski CM, Kirpilenko GG, et al. Physical and tribological properties of hard amorphous DLC films deposited on different substrates. Diamond and Related Materials 2004;13(4-8):1511-1515.

22. Baba K, Hatada R. Deposition of diamond-like carbon films on polymers by plasma source ion implantation. Thin Solid Films 2006;506:55-58.

23. Reisel G, Dorner-Reisel A. Hydrogen containing DLC coatings on UHMW-PE deposited by r.f.-PECVD. Diamond and Related Materials 2007;16(4-7):1370-1373.

24. Ozeki K, Kobayashi S, Hirakuri KK, Aoki H, Fukui Y. Oxygen plasma pre-treatment improves the wear properties of a diamond-like carbon film coated on UHMWPE and PMMA for biomaterials. Bio-Medical Materials and Engineering 2007;17(3):175-182.

25. Rico VJ, Yubero F, Espinos JP, Cotrino J, Gonzalez-Elipe AR, Garg D, et al. Determination of the hydrogen content in diamond-like carbon and polymeric thin films by reflection electron energy loss spectroscopy. Diamond and Related Materials 2007;16(1):107111.

26. Lewis G. Contact stress at articular surfaces in total joint replacements. Part I: Experimental methods. Bio-Medical Materials and Engineering 1998;8(2):91-110.

27. Szivek JA, Anderson PL, Benjamin JB. Average and peak contact stress distribution evaluation of total knee arthroplasties. J Arthroplasty 1996;11(8):952-963.

28. da Silva CH, Sinatora A. Development of severity parameter for wear study of thermoplastics. Wear 2007;263:957-964.

29. Muratoglu OK, Ruberti J, Melotti S, Spiegelberg SH, Greenbaum ES, Harris WH. Optical analysis of surface changes on early retrievals of highly cross-linked and conventional polyethylene tibial inserts. J Arthroplasty 2003;18(7):42-47.

30. Sheeja D, Tay BK, Lau SP, Nung LN. Tribological characterisation of diamond-like carbon coatings on Co-Cr-Mo alloy for orthopaedic applications. Surface \& Coatings Technology 2001;146:410-416.

31. Ronkainen H, Varjus S, Koskinen J, Holmberg K. Differentiating the tribological performance of hydrogenated and hydrogen-free DLC coatings. Wear 2001;249(3-4):260-266. 32. Sawae Y, Murakami T, Chen J. Effect of synovia constituents on friction and wear of ultra-high molecular weight polyethylene sliding against prosthetic joint materials. Wear 1998;216(2):213-219.

33. Gispert MP, Serro AP, Colaco R, Saramago B. Friction and wear mechanisms in hip prosthesis: Comparison of joint materials behaviour in several lubricants. Wear 2006;260(12):149-158.

34. Tsubone D, Hasebe T, Kamijo A, Hotta A. Fracture mechanics of diamond-like carbon (DLC) films coated on flexible polymer substrates. Surface \& Coatings Technology 2007;201(14):6423-6430. 
35. Zhu C, Jacobs O, Jaskulka R, Koller W, Wu W. Effect of counterpart material and water lubrication on the sliding wear performance of crosslinked and non-crosslinked ultra high molecular weight polyethylene. Polymer Testing 2004;23(6):665-673.

\section{FIGURE CAPTIONS}

Figure 1. Typical visible Raman spectrum of the DLCH coating.

Figure 2. Hardness profile of the DLCH coated pristine UHMWPE samples ( ' ) V, (---) V250, (-) V700 and on crosslinked UHMWPE ( $\left.{ }^{\cdots}\right)$ I, (---) I250,( - ) I700

Figures 3A-B. Evolution of the average friction coefficients during the ball-on-disk test for uncoated and DLCH coated virgin (a) and crosslinked (b) UHMWPE disks.

Figures 4A-F. Confocal microscopy images of the wear tracks corresponding to virgin (a), crosslinked (b), $250 \mathrm{~nm}$ thick DLCH coated virgin (c), $250 \mathrm{~nm}$ thick DLCH coated crosslinked (d), $700 \mathrm{~nm}$ thick DLCH coated virgin (e), and $700 \mathrm{~nm}$ thick DLCH coated crosslinked (f) UHMWPEs.

Figures 5A-C. ESEM images of the surface topography of uncoated (a), 250nm DLCH coated (b), and $700 \mathrm{~nm}$ DLCH coated (c), virgin samples before wear testing.

Figures 6A-F. ESEM images of the surface topography of the wear track after tribological testing for each material group: virgin (a), crosslinked (b), $250 \mathrm{~nm}$ thick DLCH coated virgin (c), $250 \mathrm{~nm}$ thick DLCH coated crosslinked (d), $700 \mathrm{~nm}$ thick DLCH coated virgin (e), and 700 nm thick DLCH coated crosslinked (f) UHMWPEs.

Figures 7A-B. ESEM images of cross-sections of V700 samples corresponding to areas out of the wear track region (a), and right on the wear track (b). 
FIGURE 1

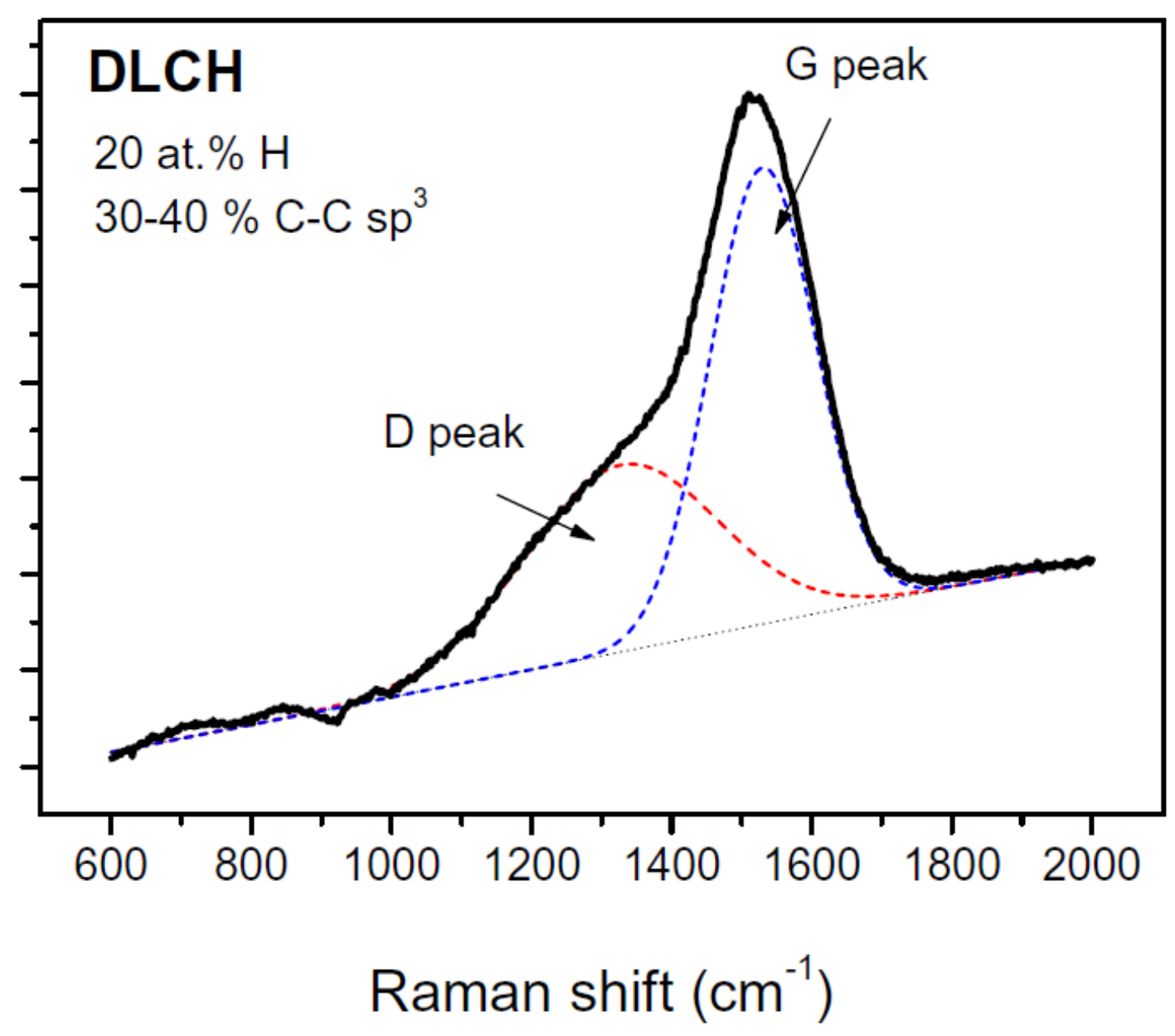


FIGURE 2

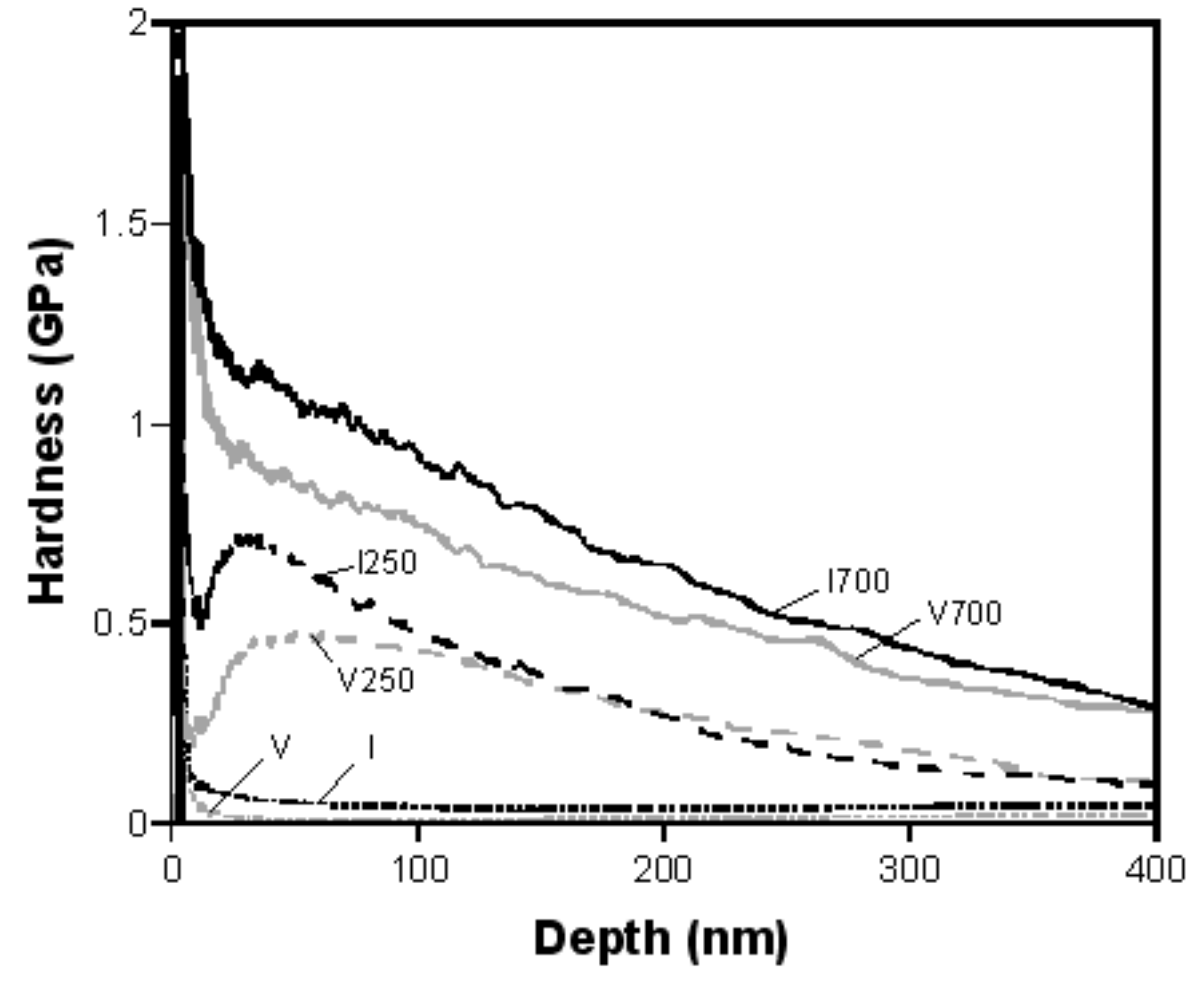




\section{FIGURES 3A-B}
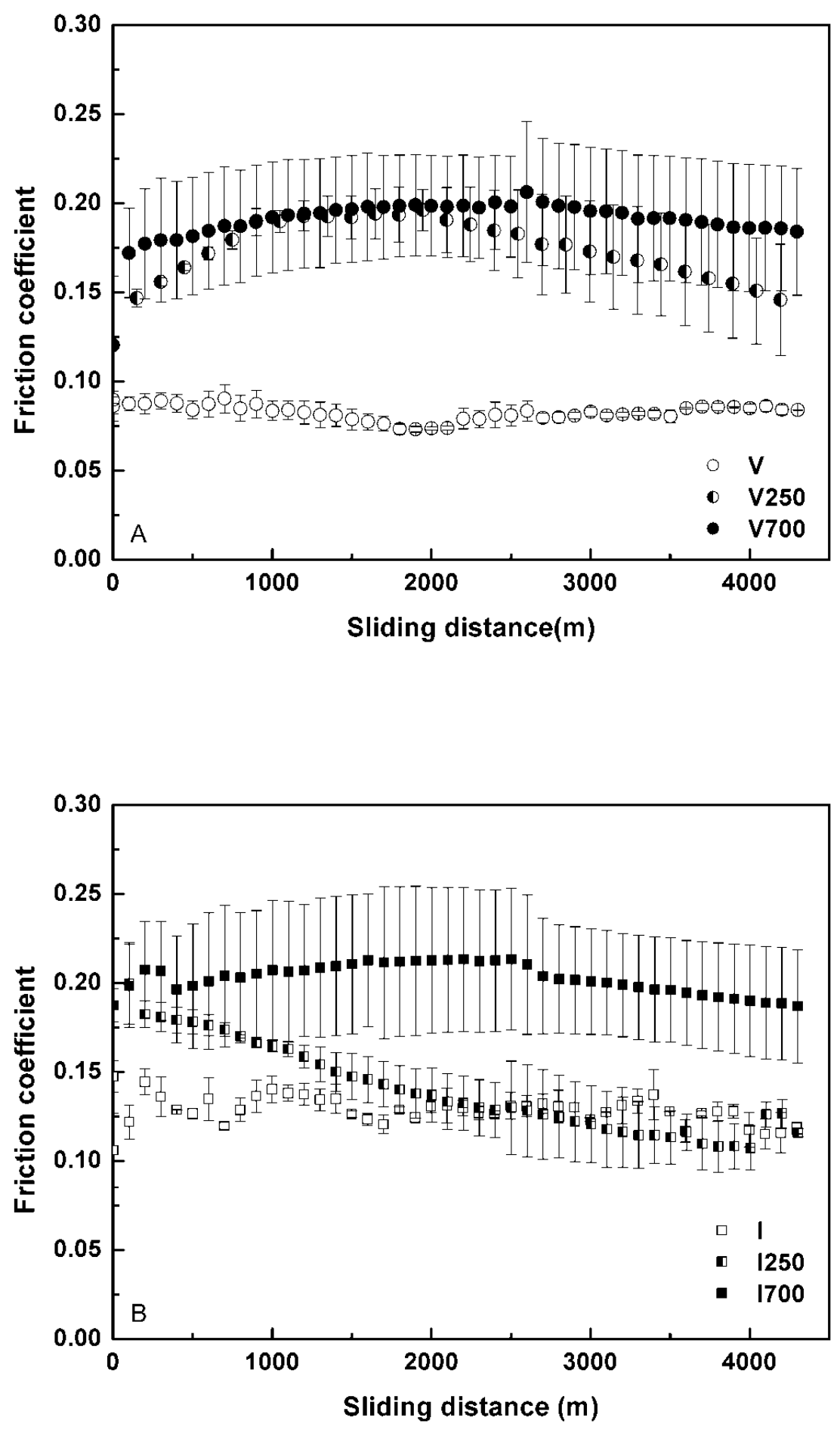


\section{FIGURES 4A-F}
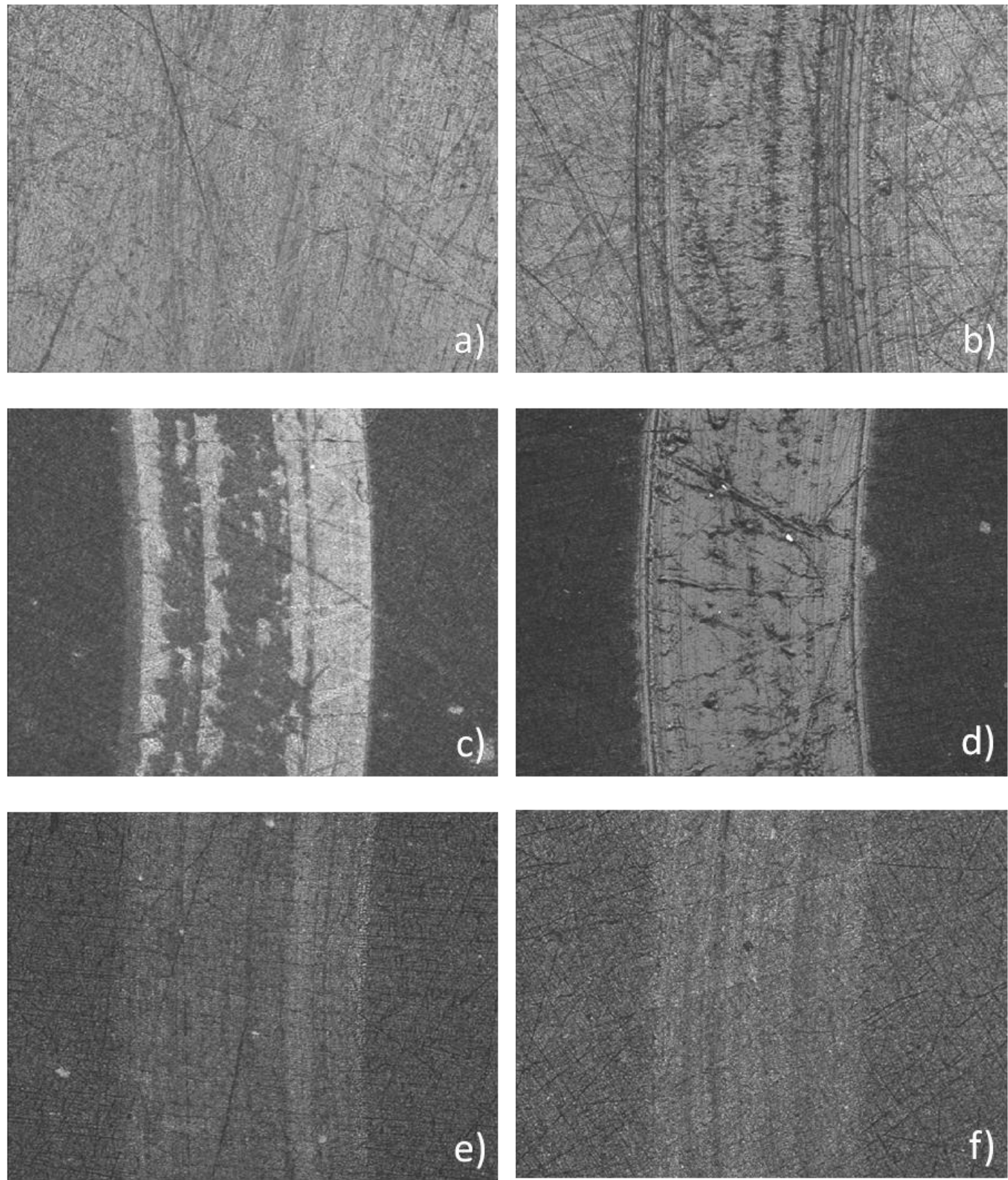
FIGURES 5A-C
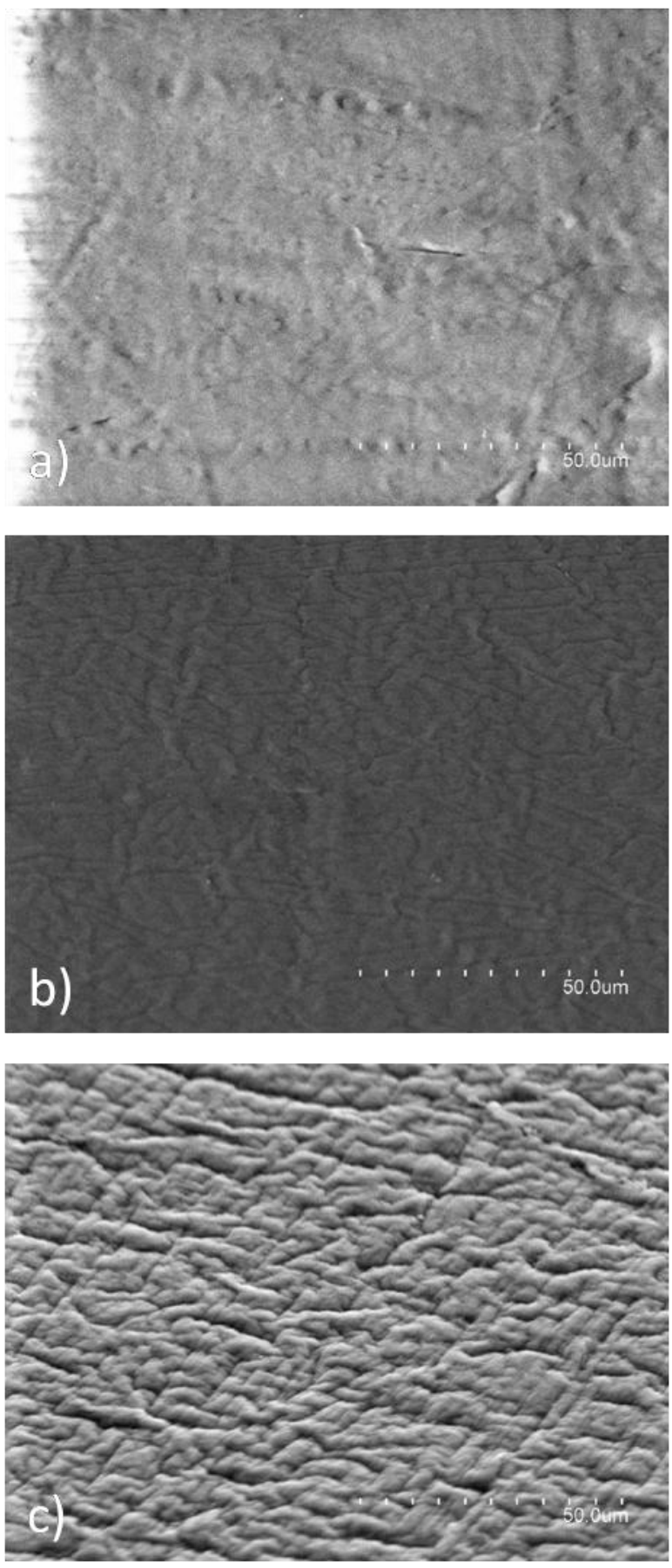
FIGURES 6A-F
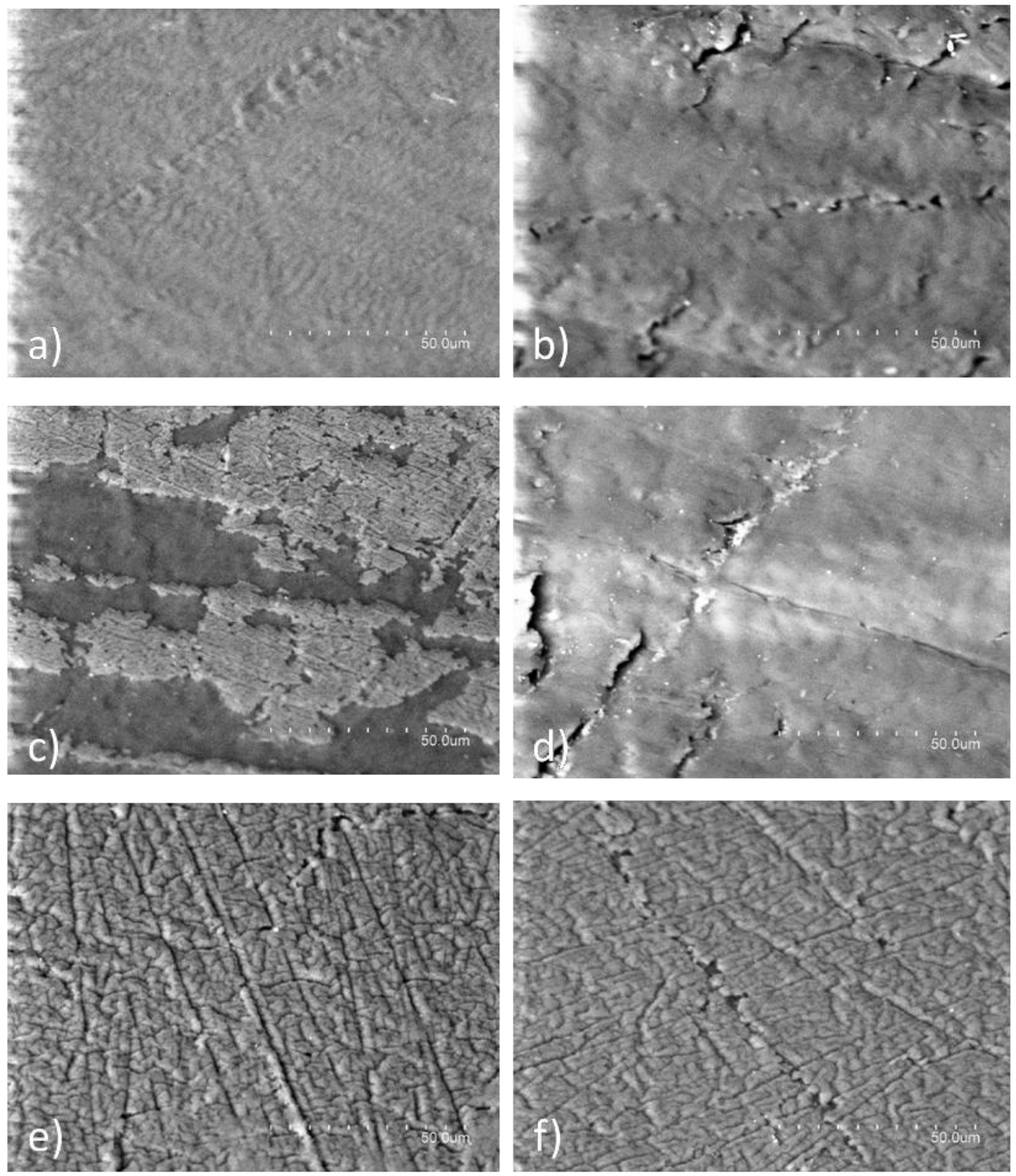
FIGURES 7A-B
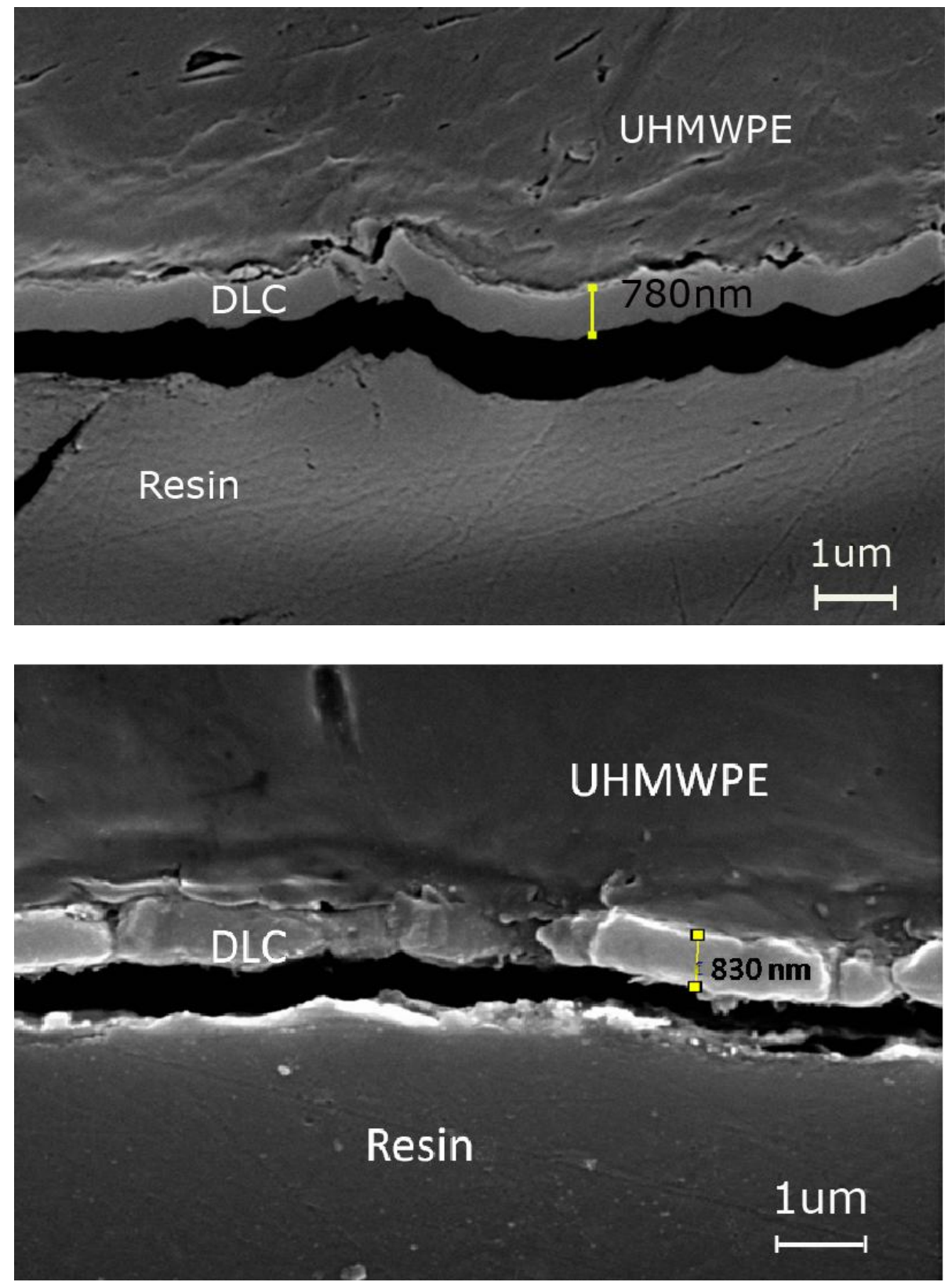
Table 1 . Wear rate, $k$, of uncoated and DLCH coated materials after different sliding distances.

\begin{tabular}{|l|ccc|}
\hline \multicolumn{4}{|c|}{ WEAR RATE, $\boldsymbol{k}^{*} \mathbf{1 0}^{-\mathbf{6}}\left(\mathbf{m m}^{\mathbf{3}} / \mathbf{~ N} \cdot \mathbf{m}\right)$} \\
\hline LENGTH(m) & $\mathbf{1 2}$ & $\mathbf{6 8}$ & $\mathbf{4 4 0 0}$ \\
\hline V & $23 \pm 32$ & $18.5 \pm 7$ & $2.4 \pm 0.1$ \\
\hline V250 & - & - & $2.6 \pm 0.5$ \\
\hline V700 & - & - & - \\
\hline I & $72 \pm 26$ & $12.8 \pm 8.2$ & $3.5 \pm 0.2$ \\
\hline I250 & - & - & $3.0 \pm 0.2$ \\
\hline I700 & - & - & - \\
\hline
\end{tabular}




\section{REVIEWER}

\section{1) NAOHIDE TOMITA}

Graduate School of Engineering, Kyoto University

ntomita@iic.kyoto-u.ac.jp

He is working in tribology related to UHMWPE for joint prostheses

2) J. L. TIPPER

Institute of Medical \& Biological Engineering, University of Leeds UK

\section{j.1.Tipper@leeds.ac.uk}

She is a relevant researcher in wear behaviour of bearing materials for total joint replacements. 